\title{
A web-based GIS for managing and assessing landslide data for the town of Peace River, Canada
}

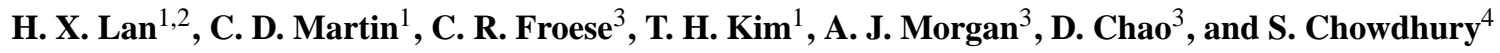 \\ ${ }^{1}$ Dept. of Civil \& Environmental Engineering, University of Alberta, Edmonton, AB T6G 2W2, Canada \\ ${ }^{2}$ LREIS, Institute of Geographic Sciences and Natural Resources Research, Chinese Academy of Sciences, Beijing, China \\ ${ }^{3}$ Alberta Geological Survey/Energy Resources Conservation Board, 4th Floor, Twin Atria Building, \\ Edmonton, AB, T6B 2X3, Canada \\ ${ }^{4}$ Dept. of Computer Science and Geographic Information Systems, University of Lethbridge, Lethbridge, Alberta, Canada
}

Received: 2 February 2009 - Revised: 31 May 2009 - Accepted: 3 June 2009 - Published: 14 August 2009

\begin{abstract}
Assessment of geological hazards in urban areas must integrate geospatial and temporal data, such as complex geology, highly irregular ground surface, fluctuations in pore-water pressure, surface displacements and environmental factors. Site investigation for geological hazard studies frequently produces surface maps, geological information from borehole data, laboratory test results and monitoring data. Specialized web-based GIS tools were created to facilitate geospatial analyses of displacement data from inclinometers and pore pressure data from piezometers as well as geological information from boreholes and surface mapping. A variety of visual aids in terms of graphs or charts can be created in the web page on the fly, e.g. displacement vector, time displacement and summaries of geotechnical testing results. High-resolution satellite or aerial images and $\mathrm{Li}-$ DAR data can also be effectively managed, facilitating fast and preliminary hazard assessment. A preliminary geohazard assessment using the web based tools was carried out for the Town of Peace River.
\end{abstract}

\section{Introduction}

Rapid urban development over the past 50 years has increased the risk of communities to geohazards such as landslides, subsidence, rock falls, avalanches, frost, river icejams, earthquakes, and flooding. Such events can have devastating consequences for any municipality as infrastructure can be severely damaged. Recent studies have shown that during the 20th Century many of the casualties reported after

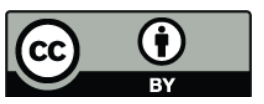

Correspondence to: $\mathrm{H}$. X. Lan (hlan@ualberta.ca) rain storms, large floods and earthquakes are actually caused by landslides generated by these events (Fig. 1: Solheim et al., 2005). In today's risk adverse society, communities are expected to identify geohazards that affect their existing and planned developments and infrastructure and prepare zoning maps based on these geohazards, as part of their infrastructure risk management and emergency response planning.

Geological hazards are complex processes involving both surface and subsurface conditions and their interactions with triggering factors (Renaud, 2000; Krahn, 2003). For many communities assessing risk associated with geological hazards is challenging, as there are often no formal guidelines for such procedures. Their assessment demands a thorough understanding of site characterization technology and complex geological processes in spatial and temporal environments (Tsai and Frost, 1999; Parsons and Frost, 2002). It is therefore important to accurately capture the essential features determined from the site characterization. Often a municipality will have a long history of site investigations with respect to geotechnical and environmental issues that is largely paper based for specific projects/issues. The challenge is to synthesize this data into a common format that can be readily accessed by geo-engineering professionals. As noted by Morgenstern and Martin (2008), such synthesis can often lead to an enhanced understanding of the ground. Culshaw (2005) reviewed the advances in technology that have taken place over the pass 20 years to facilitate data integration and outlined the developments needed to advance the technology to routine site investigations. Culshaw (2005) also noted that an enhanced understanding of ground conditions leads to better definition of hazard zoning in urban environments, linking hazard, infrastructure and risk, and an improved recognition where mitigation is required.

Published by Copernicus Publications on behalf of the European Geosciences Union. 


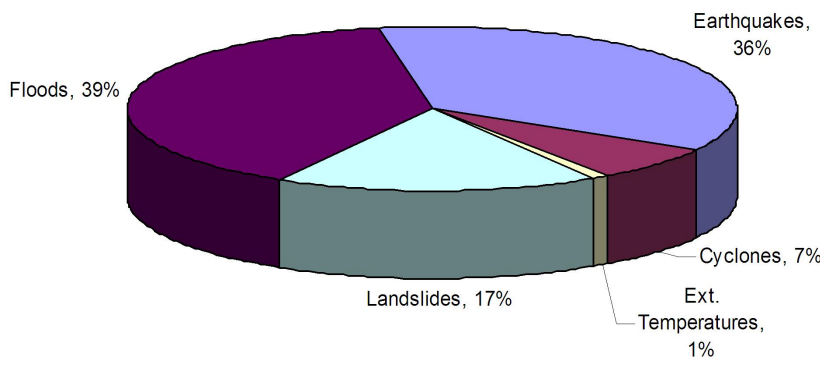

Fig. 1. Comparison of casualties from different hazards in the 20th century (Source: EM-DAT: The OFDA/CRED International Disaster Database.

New technologies are needed to facilitate synthesis of data from site investigation and characterization for geological hazard assessment in urban areas (Culshaw, 2005). While there are many technologies in use today, the geographic information system (GIS) is increasingly viewed as a key tool for managing spatial and temporal data for natural hazards (Nathanail, 1998; Kimmance et al., 1999; Parsons and Frost, 2000; Lan et al., 2004, 2005; Kunapo et al., 2005; Forte et al., 2005; Köhler et al., 2006). Similar approach has been widely used for managing data for tunnel construction in the urban area, for example the GDMS (Geodata Data Management System) developed for Porto and Torino Metro projects (Guglielmetti et al., 2008). Engineers responsible for hazard assessments could benefit through cross-fertilization and mutual support of different technologies (Brimicombe, 2003) and obtain more useful and robust solution by effectively using various types of data. In this paper we describe a web-based GIS framework that was used to managing various kinds of data related to landslides in the Town of Peace River, Canada. Specialized tools were developed that facilitated geospatial and temporal analyses of displacement data from inclinometers and pore pressure data from piezometer as well as geological information from borehole logs and surface mapping. A variety of $x-y$ plots can be created in the web page on the fly, e.g. displacement vector, time displacement and other geotechnical test graphs. The web-based GIS can also effectively manage high resolution satellite or aerial images and LiDAR data.

\section{Web-GIS development}

The Town of Peace River (Fig. 2) has been exposed to both flooding and landslide hazards since initial settlement almost 100 years ago (Ruel 1988; Cruden et al., 1990). In contrast to many settlements located along the Peace River, the Town of Peace River is situated on the broad flood plains in the river valley bottom and on the unstable valley walls. Complex geology, including buried valleys (Cruden et al., 1997) as well as microclimatic conditions add to the complexity of possible geological hazards in this area. Significant growth of the

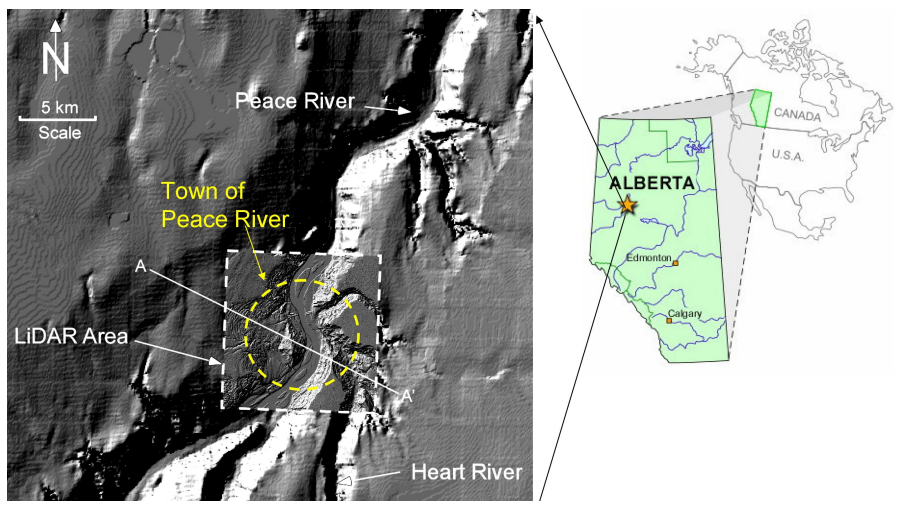

Fig. 2. Location of the Town of Peace River, Alberta. The map in the left corner shows shaded digital elevation model derived from SRTM (Shuttle Radar terrain Model) and LiDAR (Light Detection And Ranging) Datasets.

Town of Peace River during recent years resulted in urban developments in areas that may be more vulnerable to geological hazards than considered during the design/planning. It is important that these locations are identified and stakeholders informed about these geohazards and associated consequences. In 2006 a project was initiated to provide a better understanding of the landslide processes and extents for the stakeholders, of which the development of a web-based tool for visualizing data was required (Froese, 2007). The web based system concentrates on improving the understanding of the extent, rate and drivers for landslide geohazards in this area.

\subsection{System framework}

Lan and Martin (2007) outlined a work flow for general geotechnical engineering problems (Fig. 3). It can be summarized in three stages:

1. Stage 1 involves the data collection, management and synthesis.

2. Stage 2 is the development of a comprehensive ground model that includes ground behaviour and

3. Stage 3 is the engineering analyses.

The web-based GIS tools were designed to facilitate the tasks in Stage 1. The data handled in Stage 1 could be basic site investigation data (such as geomorphology and geology conditions) and diverse, continually evolving geotechnical parameters (such as displacement and pore pressure readings from geotechnical instruments). The tasks in this stage involve data collection, data design, data integration, data presentation, data visualization and data communication.

GIS (Geographic Information System) technology provides effective tools for the handling, integrating and visualizing diverse spatial data sets (Brimicombe, 2003). The functionalities of web-based GIS technology play an essential 


\begin{tabular}{|c|c|c|}
\hline \multicolumn{3}{|c|}{ STAGE 1: Data Collection, Management \& Synthesis } \\
\hline Input Data: & Synthesis Tools: GIS & Output: \\
\hline $\begin{array}{l}\text { - Base DEM data } \\
\text { - Topography } \\
\text { - Lidar/Photogrammetry } \\
\text { - Engineering Dwgs } \\
\text { - Geology/Geoophysics } \\
\text { - Borehole } \\
\text { - Surfacial } \\
\text { - Displacements } \\
\text { - Inclinometers } \\
\text { - EDM } \\
\text { - Groundwater } \\
\text { - Piezometers } \\
\text { - Precipitation/temp. } \\
\text { - Field Observations }\end{array}$ &  & $\begin{array}{l}\text { - Data integration } \\
\text { - Data presentation } \\
\text { - Data visualization } \\
\text { - Data communication } \\
\text { - Ground Modelling } \\
\text { - Performance reports } \\
\text { - Sensor data }\end{array}$ \\
\hline
\end{tabular}
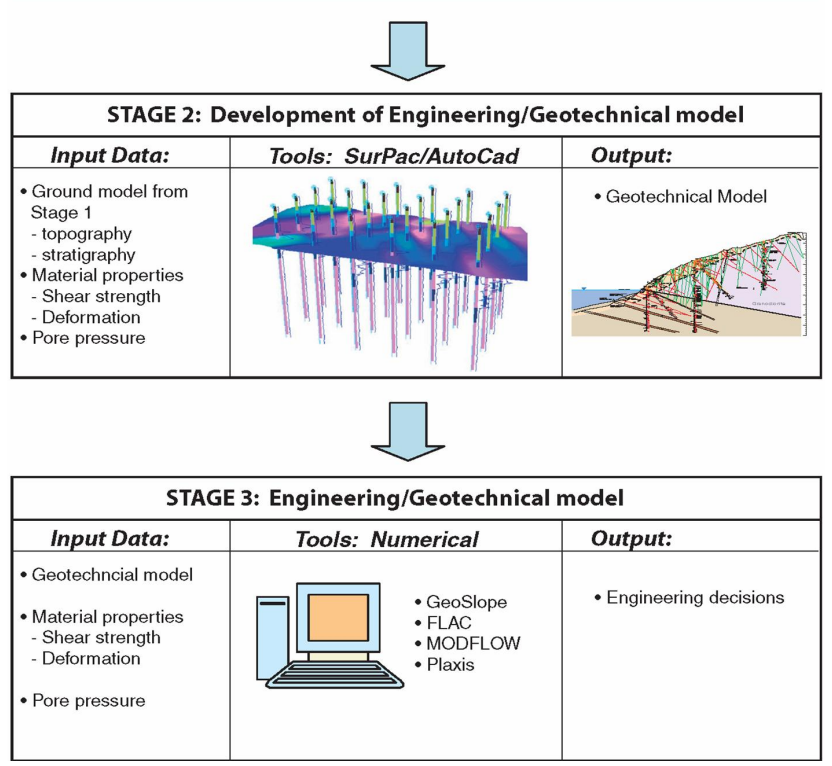

Fig. 3. The architecture of integrated system for geotechnical engineering solution. It is composed of three different stages which required the implementation of specific tasks (modified from Lan and Martin,2007).

role in Stage 1 in collecting, storing analyzing, visualizing and disseminating geospatial information. However, most GIS tools have limitations in representing time series data such as the displacement data from inclinometer or pore pressures from piezometers. Additional functional tools were required to address these deficiencies and were implemented as add-on functions to commercial GIS software. These tools provide capability for users to interact and communicate with various geotechnical data sets.

A three-tier architecture has been used for the geohazards Web-GIS system (Fig. 4): Database tier, Server tier and Client tier. The users in Client tier are acting as terminals via the Internet/Intranet. Some users such as public users could simply use internet browsers (Internet explorer or Firefox) to access the data and functions which the server provides. Other professional users such as consulting companies, government agencies or university researchers could use more powerful desktop tools (i.e. ArcMap) to access the Server and perform sophisticated tasks. The customized tools are

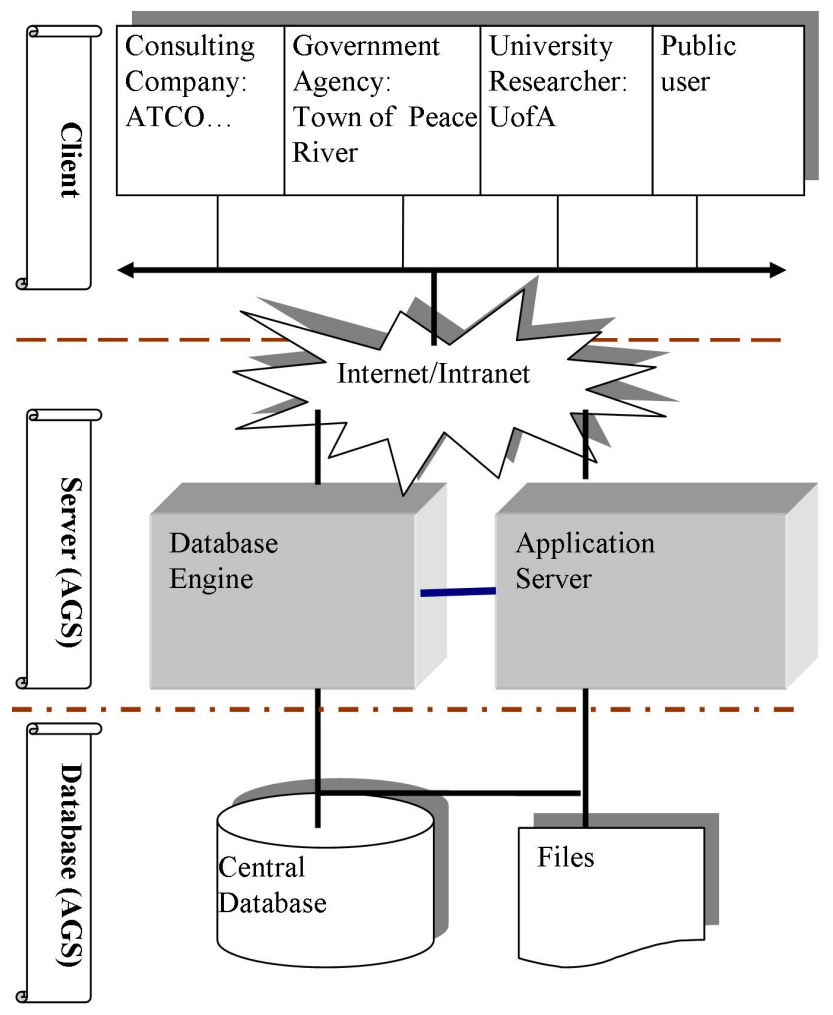

Fig. 4. Diagram for Web-based GIS System architecture.

shown as toolbar extended to the desktop package. ArcGIS Server, one of server GIS products from ESRI was chosen as the basic platform for the server application. It offers open Web access to maps, analyses, models, and facilities to add user functionality. It is a server-based GIS that enables organizations to share information through focused, easyto-use Web services and applications. The additional functions were implemented as add-on tools linked to the application server using ADF (Application Development Framework) development Kit and Visual studio.net, a software developing package by Microsoft. The use of a database engine (such as ArcSDE) can boost the efficiency and speed of data access. A database engine was not used at the initial stage of Peace River project, but may be employed in the future as the amount of data increases.

\subsection{Database}

Web-based central database was used in the system to enable effective data collecting, maintaining, upgrading and communicating. It is the core component for the Peace River System (PRS). The project is based on the historical and recent data available from the Town of Peace River that have been collected over the past 30 years. These data include borehole data, geotechnical parameters, field mapping, testing, monitoring, groundwater information and geophysical investigations and reports. Data from over 1400 boreholes 


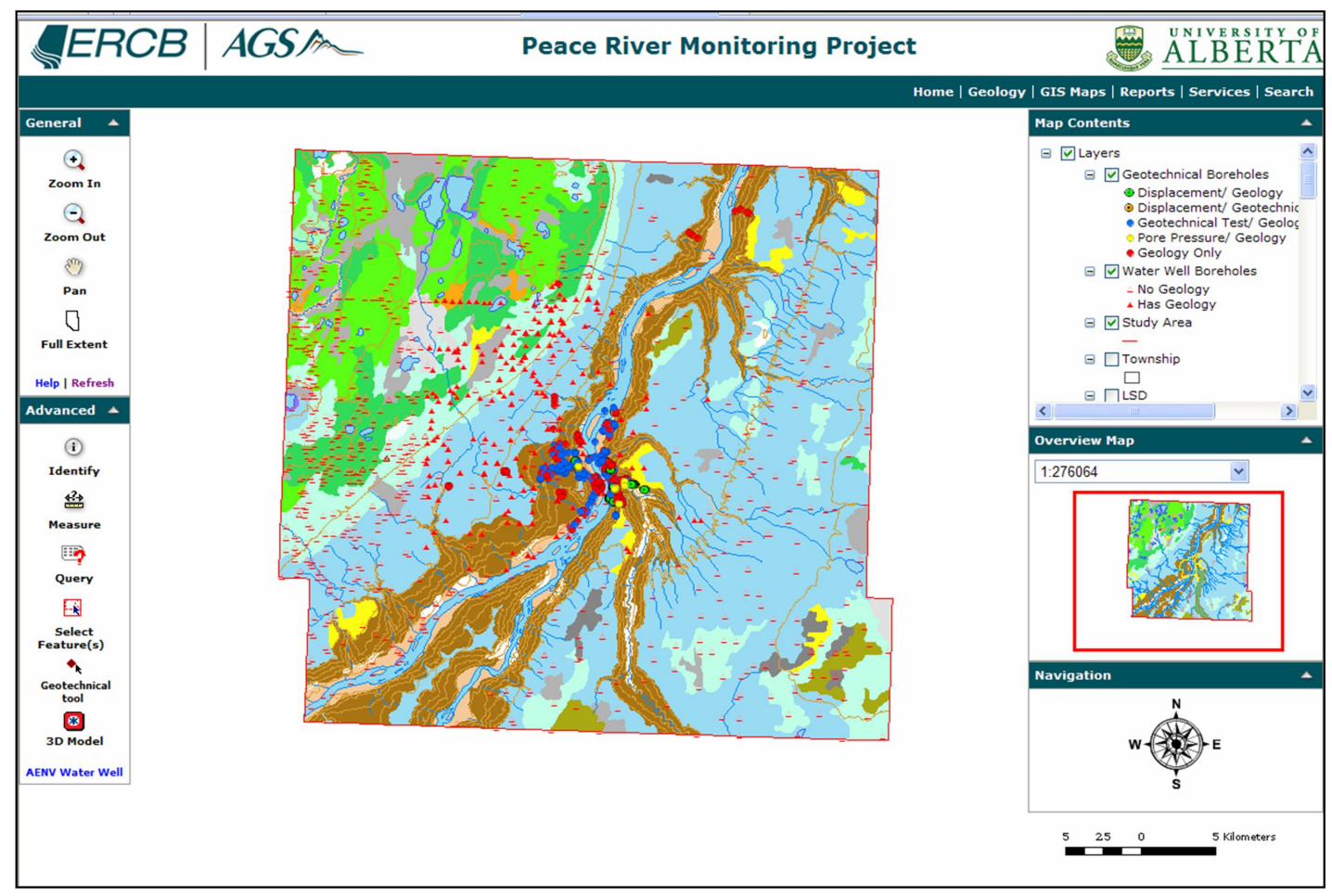

Fig. 5. Interface of Web-GIS for Peace River Project.

Table 1. Database structure for Geology and slope Inclinometer readings. The fields in bold are key fields jointing different data tables.

\begin{tabular}{llll}
\hline $\begin{array}{l}\text { Geology } \\
\text { data structure }\end{array}$ & \multicolumn{3}{c}{ Inclinometer data structure } \\
\hline Collar & Installation & Survey & Data \\
\hline Hole_id & InstID & Pointer & Pointer \\
X & Site & Rdg_Set & Rdg_set \\
Y & Inst & Date_Read & Depth \\
Z & Desc & Time_Read & A_0 \\
Max_depth & SerialNum & Full_Set & A_180 \\
Hole_path... & A0Dir & Actl_Sens & B_0 \\
Geology & Deep & Rot_Corr_A & B_180 \\
Hole_id & Shallow & Rot_Corr_B & \\
Depth_from & Interval & Actl_Cnst & \\
Depth_to & InitDate & Operator & \\
Lithology & Azimuth & Spiral & \\
Elev & Stickup & Num_Depth & \\
Code... & DataLoaded & Include & \\
& InstrConstant & Exclude & \\
& offsetA... & ... & \\
\hline
\end{tabular}

were available in this area in terms of geotechnical borehole, oil and gas wells and groundwater wells. The long history of the geohazards encountered in the Town of Peace River has created rich data legacy. That data existed in the form of consulting and government agency reports, mainly in hard copy (paper) format. The Alberta Geological Survey (AGS) undertook the task of collecting and processing the primary data. All the data were digitized and input into a central database located in a database server in AGS.

The data related to geohazard site investigation can be categorized into three classes: (1) geospatial data and (2) nonspatial attribute data and (3) temporal data. The geospatial data involves the slope surface, slope boundary, subsurface geology, groundwater conditions, and borehole location, location of rainfall gauges and location of other infrastructure, such as roads, buildings, and utilities. Non-spatial data consists of attribute information that mainly includes borehole details information (collar coordinates and downhole survey information) and geotechnical parameters from laboratory or field test. The temporal data are related to environmental data, such as rainfall and monitoring data from instrument, such as displacement monitoring and water pore pressure. All the data can be a relational database based on standard geotechnical structure and linked to the geospatial layers. Table 1 shows an example of the standard structure for managing inclinometer data and geological data in a relational database. Each dataset is composed of multiple tables 




Fig. 6. Sample result for specialized geotechnical tools which shows the different plot for inclinometer readings. The displacement vectors are shown directly on the plan map.

managing different information. For example, inclinometer dataset consists of table of installation, survey and data. This database structure is fairly standard today and is supported by many engineering software packages. Different datasets are related each other using key field. A central storage location for data with restricted access minimizes the chances for data errors.

\subsection{Interface and functions}

The main Peace River System interface is shown in Fig. 5. All the information has been integrated seamlessly into the website. Access to the GIS server is embedded inside the web application and typically hidden from the user of the application. Three different panels are divided in the user interface: the left functional panels, middle map panel and right data managing panels. The middle and right zones are responsible for data management and data displaying. By turning on different layers on the right panel, various datasets can be quickly and seamlessly displayed in the middle map panel. The high resolution imagery such as Quickbird images and LiDAR (Light Detection and Ranging) data can also be easily managed.

The left panel contains general and advanced GIS toolsets for performing navigations, data queries, specialized anal- yses and 3-D model manipulations. The general toolset includes navigational functions such as zoom in, zoom out, pan and full extent. A Help and Refresh for redrawing map layers are also part of the toolset. The advanced toolset consists of more sophisticated tools such as querying features in a dataset individually (Identify), by selecting multiple features interactively based on the spatial location (Select Feature(s)), and by specifying search criteria based on dataset attributes (Query). The 3-D Model tool enables user to manipulate and view high resolution remote sensing images such as RadarSat, QuickBird, Orthophoto, LiDAR and Digital Elevation Model (DEM) at $360^{\circ}$.

A customized geotechnical data analysis tool called Geotechnical Tool was developed to improve the efficiency of site investigation and site characterization for geohazard assessment. Users can use this tool to explore geotechnical information of any boreholes in the map panel. Geotechnical information includes time-series displacements from inclinometers, pore pressures from piezometers, geotechnical test results and stratigraphy from geological/geotechnical logging.

The Geotechnical Tool provides all of the standard types of plots for analyzing slope inclinometer data. The user can quickly check the cumulative displacement plot and 




Fig. 7. Example of comparing different datasets: Inclinometer data versus geological stratigraphy and geotechnical test data.

incremental displacement plot. From these standard plots discrete movement zones can be defined by specifying the from-to-depths. The resultant time-displacement plots for these discrete zones show acceleration or deceleration of slope movement. In addition to the displacement versus time plots, plots of displacement vector directions and displacement rate offer the ability to identify and evaluate the spatial and temporal character of the deformations (Fig. 6).

In order to quickly and easily compare different dataset, dataset plots can be created in a single form. Figure 7 shows a comparison plot for deformation data, geological data and geotechnical test.

\section{Application and discussion}

An understanding of the deformation process is an essential part of landslide hazard assessment. This process understanding should involve not only comprehensive assessment spatially, but temporally. Landslide problems in an urban setting usually develop as the urban infrastructure grows. Hence landslide investigations are usually carried out over decades at various locations. As discussed in the previous part, central database has been established in dealing with the spatial and the temporal data and multi-level clients can connect to it. With the support of web-based GIS tools, different-level assessments can be conduced in addition to the general map- ping. When conducting studies of multiple landslide events, the first step is to synthesize the available baseline of data. Such synthesis can reveal the ground deformation patterns in space and history in time. These deformations directly impact infrastructure such as pipelines and roads. Using the data available for the Town of Peace River a preliminary geohazard assessment was carried out using the information extracted from the historical records. The process used to enable this assessment is described below.

\subsection{Landslide catalogue}

One of the first steps for the project was the transfer of the documented landslides from the historical paper format to the digital database. These historic landslides first had to be geo-referenced and the relevant data compiled and entered into the database. The effort for this was significant as instrumentation data and geotechnical laboratory test data also had to be compiled and checked. Figure 8 shows the inventory of the historical landslides impacting on the Town of Peace River combined with high resolution LiDAR and optical Quickbird imagery. The bare-earth model from the 2007 LiDAR also still captures the outline of the historic landslides even though some of these landslides happened more than 20 years ago. The web-based GIS tools provides an excellent means of communicating to the stakeholders the spatial location and temporal distribution of these historic landslides 
Table 2. Example of Landslide Inventory in the Town of Peace River

\begin{tabular}{cllll}
\hline ID & Location & occurrence year & Type \\
\hline 1 & Mile 47.8 & Late 1993 to early 1994 (Landslide) 1994 (minor derailment) & Translational block slide and Single rotational slide \\
2 & Mile 47.6 & June, 1984 (Landslide) July, 1985 (Large settlement) April, 1987 (Toe berm failure) & Translational block slide \\
3 & Mile 46.5 & & Spring 1978 (Tension cracks) May, 1980 (Landslide) & Translational block slide \\
& & End of 101 st. & Jan., 1992 (Slope movement) 1993 (Accelerated) & Translational block slide \\
4 & $99 / 101$ st. & End of 99 st. & Oct., 1985 (Landslide) 1988-1989 (Landslide) & Translational block slide \\
& & Transition zone & Late June-early July, 1973 (Landslide) Jan., 1992 (Slope movement) & Translational block slide \\
5 & Shop slide & 1985-1986 (Slope movement) 2005 Max (Accelerated) & Translational block slide \\
6 & Mile 50.9 & 3 May 1979 (Landslide) & Flow (relatively slow, moderately slow) \\
\hline
\end{tabular}



Fig. 8. The landslides distribution in Peace River valley. The maps on the top show the oblique view of the Shop slide (left) and 99/101 slide (right). The map in the bottom right shows the temporal distribution of the Landslide occurrences.

even though many of the slides may not be active now. Figure 8 shows spatial and temporal distribution of 8 landslides in 6 sites along the river valley and Table 2 shows the location, occurrence time and sliding type of these 8 landslides. The top figures in Fig. 8 shows the oblique view of two specific slides that will be discussed in more detail below: the Shop slide (left) and 99/101 Street slides (right).

There are a significant number of landslide related problems along both west and east bank of Peace River. Two examples of such landslides are the Shop Slide, which occurs on the west valley wall and the 99/101 Street slides on the east valley wall (Fig. 8). For each of these slides the scarps and major translational blocks moving along the rupture surfaces can be easily identified from the high resolution digital elevation model from LiDAR data, which can be viewed in both 2-D and 3-D views in the web-GIS tools.

\subsubsection{Shop Slide}

The Shop Slide is located along the old Highway 2 climbing the valley wall of the Peace River. The road consists of cut and fill, and has $30 \mathrm{~m}$ height and 4:1 (horizontal vs. vertical) slope inclination. The general subsurface stratigraphy of the Shop slide consists of a lacustrine clay deposit, till deposit and bedrock formation (Fig. 9). Clays deposited on top of the slope may be mixed with the embankment fill used for the road construction. Beneath the clay fill, the post glacial lacustrine clay is underlain by glacially deposited 




Fig. 9. Cross section of the Shop Slide (A-B). The location of section is shown in Fig. 8.

overconsolidated clay till deposits. The clay shale bedrock encountered in the lowest part of the slide is part of the marine Shaftesbury formation of Cretaceous age. Some coarse material deposits including sand, silt and gravel were found in the nearly flat lying ground below the $\mathrm{CN}$ rail track (see Fig. 9).

The approximate failure surface can be estimated by the location of ground movement established in several boreholes using slope inclinometers. The failure surface is located in the clay deposits with a maximum depth of $17 \mathrm{~m}$ below ground surface adjacent to borehole TH05-03. Based on the slope inclinometer measurements, the failure surface of the Shop slide can be divided into two parts. One, which is located on the upper slope above the old Highway 2, appears to be old and less active. The other, located in the lower slope above the $\mathrm{CN}$ rail is active and directly affects the road. This information is based on the notion, from historical data for the Peace River valley, that this type of slide is expected to be a translational block slide.

\subsubsection{9/101 Street slides}

The 99/101 Street slides can be divided into three sections, end of 101 Street (A-B), end of 99 Street (E-F), and the transition zone (C-D), due to the relatively large areas affected by slope instabilities in the east bank. The end of 101 Street is located on the southern end of the residential subdivision. The topography of this area was changed in 1974 and 1975 with a large placement of fill to facilitate the development of the residential subdivision. The end of 99 Street is located north of the intersection of 99 and 101 Streets. The initial ground movement occurred in 1985. Instabilities in this area mainly consist of three different portions of slides: shallow surface slides in the slope below 99 Streets and a shallow translational slide affecting 99 Street pavement, which occurred consecutively with the surficial slide in 1985 . The

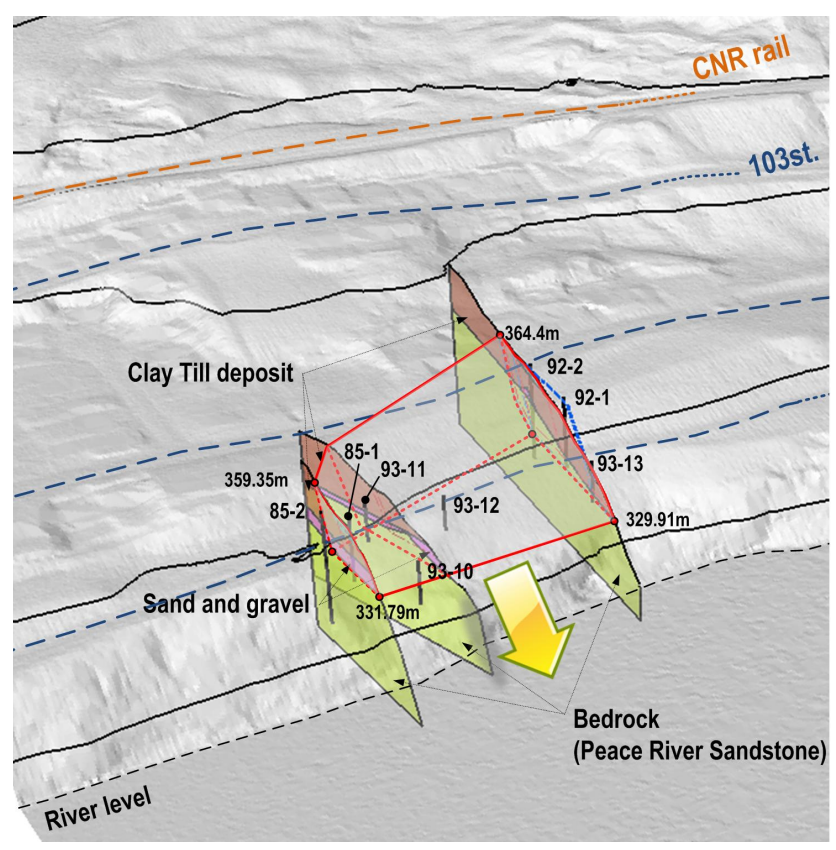

Fig. 10. Major slide blocks and their cross sections in 99 and 101 Streets slide area. The location of cross sections shown in Fig. 8.

transition zone is located a little further south from the end of 99 Street slide area (i.e. between the end of 99 and 101 Streets). The movement of the slides was observed in 1992 and accelerated in 1993. Between 1993 and 1994, a number of homes were demolished and a large berm constructed to slow movements that were impacting on the subdivision.

It is evident from the subsurface stratigraphy and borehole data that the general failure surface controlling the translational movement occurred at 99 and 101 Streets (Fig. 10). The slope instability area has an elevation of 330 to $333 \mathrm{~m}$, is located in the Shaftesbury clay shale formation and has 


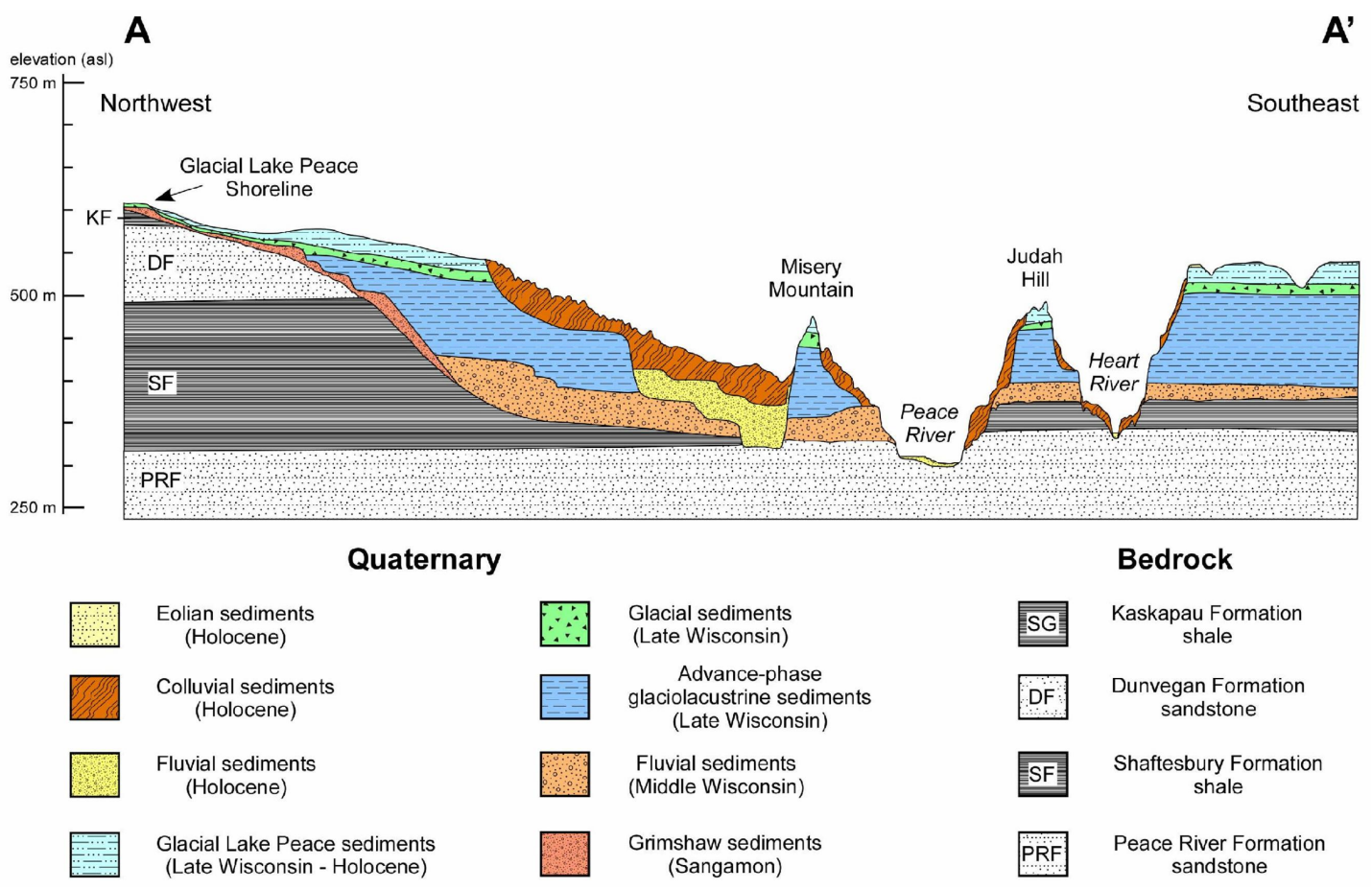

Fig. 11. General stratigraphy of the Peace River Valley, after Morgan et al. (2008). Vertical cross section A-A' as shown in the plan of Fig. 2. Horizontal distance $18 \mathrm{~km}, 12 \times$ vertical exaggeration.

at least one isolated failure surface which showed a shallow surficial slope failure caused by local weakening of the soil due to the concentrated infiltration of water. Reactivation of major slide blocks along the preexisting failure surface in the Shaftesbury clay shale formation resulted from significant modification of natural topography for the residential subdivision. The direction of the slide block is toward the river.

\subsection{Geology and landslide kinematics}

One of the major advantages of being able to systematically examine the various landslide features with the webGIS tools is the ability to explore the landslide kinematics and establish the geological factors controlling the formation of the rupture surface. The borehole data from the central database was utilized, along with field mapping, to build a regional geological model of the subsurface as well as at each landslide location. Figure 11 shows a schematic cross section of the geology at the town of Peace River, along with the stratigraphic column proposed by Morgan et al. (2008). Within this geological framework, the borehole information at each specific landslide can be utilized to determine where the landslide site fits within the larger geological framework. The inclinometer data can then be used to establish the location of the rupture surface in order to establish the kinematics of the deformation patterns.

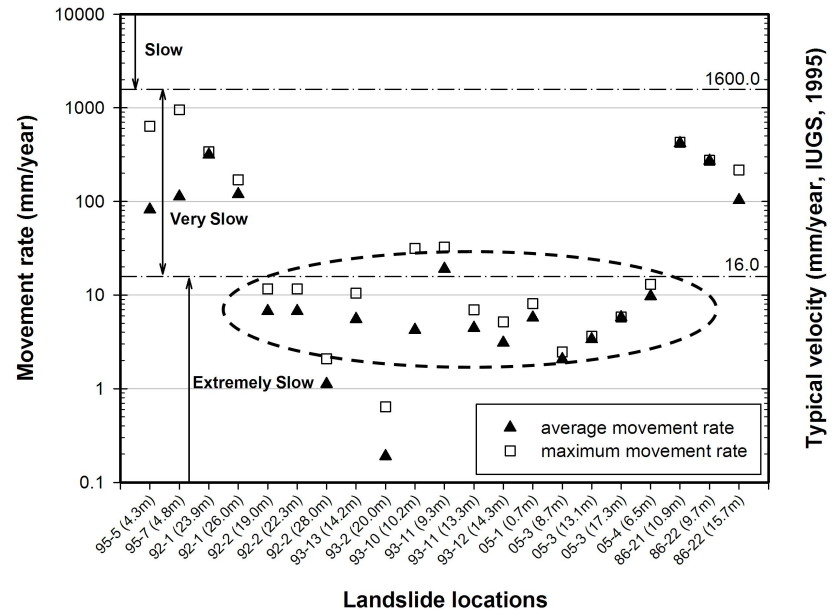

Fig. 12. Classification of Landslide movement rate of sliding mass in the Peace River valley.

Using the Web-GIS tools, the deformation velocities of shear zones for each site can be easily extracted and explored (see Figs. 6, 7). Spatial interpolation method then can be performed on these site data to create various velocity raster layers in terms of different time periods which allow visualizing the spatial variability of slope deformation (Nathanail and Rosenbaum, 1998). 


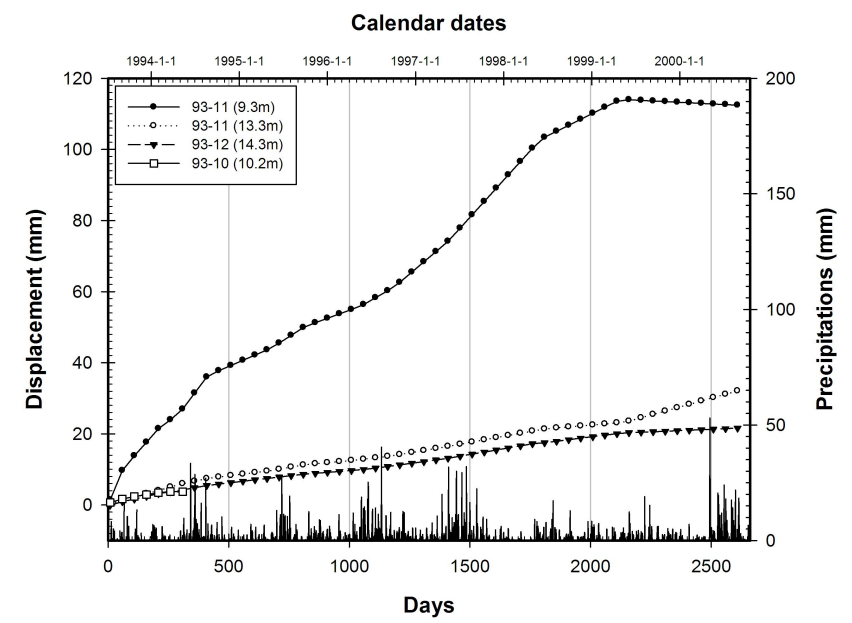

Fig. 13. Displacement or movement history of three boreholes within 99/101 Street landslide and the measured rainfall.

The site specific deformations are usually measured at points (boreholes) by slope inclinometers. The average movement rate and maximum movement rate in mm per year of a number of sites are plotted in Fig. 12. Using the system proposed by the International Union of Geological Sciences (IUGS, 1995), the velocity of the landslides in Peace River valley are generally classed as Extremely slow to Very slow. The displacement history of three boreholes, 93-10, 93-11, and 93-12 within 99/101 Street slides is shown in Fig. 13. The post failure of three locations exhibited very similar movement patterns, which indicates a similar kinematic mechanism. However, the different zones in borehole 93-11 show distinct different movement behavior. The moving rate of the shallow zone changed frequently while the deeper zone remains relatively constant, which indicates that the shallow zone is more sensitive to minor changes in boundary conditions such as rainfall. Localized small scale slope failure is more prone to occur in this shallow zone. Such information is important when evaluating the impact of these movements on existing infrastructure and evaluating various mitigative measures.

Geostatistical interpolation of the site movement data enables us to examine the spatial distribution of the slope movements measured in boreholes. Figure 14 shows the velocity distribution in October 2005 and May 2007 in the area of Shop Slide at West bank of Peace River. It can be seen that the spatial distribution of slope deformation in this region was similar for both time periods although there appears to be a slight change in the direction of slope movement. The velocity and displacement history of Site TH05-3 from October 2005 to May 2007 were also plotted. The magnitude of deformation velocity decreased in the winter season, and accelerated during the summer season (Fig. 14). These minor and subtle changes in velocity are likely related to the shallow portions of the landslide responding to the rainfall that



Fig. 14. Movement rate of Shop Slide on the west bank of Peace River. The top two raster images show the spatial distribution of velocity at two time period (October 2005 and May 2007).

occurs during the spring and early summer period. Utilizing this data with the 2-D and 3-D LiDAR images displayed in the web-GIS, zones with similar slope morphology can be used to bound data and compare movement rates in different zones of the landslides, which typically move differentially. This type of displacement information can aid in developing hazard-zoning maps for the slide.

\section{Conclusions}

In general, the assessment of geohazards in urban areas should address complex geological, geotechnical and hydrological issues. To improve the understanding of these interacting processes, new knowledge and techniques are required. Development of specialized tools, specifically tailored to link spatial and temporal data to geotechnical analysis, is needed such that parameter variability and hazard analyses can be linked. A web-based GIS tool was designed and developed to enable effective integration of data collected from site characterization. The interface and specialized tools were enhanced by providing the capability within webGIS system to interactively query and analyze the various datasets. The tools developed are specifically designed to facilitate geohazard assessment and enhance geological modeling using geological stratigraphy information and geotechnical data from traditional boreholes, landslide inventory from high resolution LiDAR and aerial photos and historical documents, and landslide kinematics using velocity information from continuous monitoring of instruments 
The sophisticated Web-GIS tool offers functions that provide better information for proactive planning and developing mitigation strategies. The tool also provides an efficient method to communicate the effect of geohazard to Stakeholders.

Acknowledgements. The authors wish to acknowledge the financial support of Natural Sciences and Engineering Research Council of Canada, ATCO Pipelines, ATCO Electric, CN and Town of Peace River. This research is also supported by One hundred talents program funded by Chinese Academy of Sciences and National Key Technology R\&D Program of China (2008BAK50B05). We kindly acknowledge Rejean Couture with Natural Resources Canada for the contribution of the Quickbird imagery for the project.

Edited by: K. T. Chang

Reviewed by: M. Jaboyedoff and another anonymous referee

\section{References}

Brimicombe, A.: GIS, environmental modelling and engineering, London, New York, Taylor \& Francis, 312 p., 2003.

Cruden, D. M., Ruel, M. S., and Thomson, S.: Landslides along the Peace River, Alberta, in: Proceedings of the 43rd Canadian Geotechnical Conference, 61-68, 1990.

Cruden, D. M., Lu, Z. Y., and Thomson, S.: The 1939 Montagneuse River landslide, Alberta. Can. Geotech. J., 34(5), 799-810, 1997.

Culshaw, M. G.: The Seventh Glossop Lecture From concept towards reality: developing the attributed 3-D geological model of the shallow subsurface, Q. J. Eng. Geol. Hydrogeol., 38, 231284, 2005.

Forte, F., Pennetta, L., and Strobl, R. O.: Historic records and GIS applications for flood risk analysis in the Salento peninsula (southern Italy), Nat. Hazards Earth Syst. Sci., 5, 833-844, 2005, http://www.nat-hazards-earth-syst-sci.net/5/833/2005/.

Froese, C. R.: The Peace River Landslide Project: Hazard and Risk Assessment for Urban Landslides, in: Proceedings of the 60th Canadian Geotechnical Conference, Ottawa, Ontario, 699-704, 2007.

IUGS-International Working Group, Landslide: A suggested method for describing the rate of movement of a landslide, Bull. Eng. Geol. Environ., 52, 75-78, 1995.

Kimmance, J. P., Bradshaw, M. P., and Seetoh, H. H.: Geographical Information System (GIS) Application to Construction and Geotechnical Data Management on MRT Construction Projects in Singapore, Tunnelling Underground Space Tech., 14(4), 469479, 1999

Köhler, P., Müller, M., Sanders, M., and Wächter, J.: Data management and GIS in the Center for Disaster Management and Risk Reduction Technology (CEDIM): from integrated spatial data to the mapping of risk, Nat. Hazards Earth Syst. Sci., 6, 621-628, 2006, http://www.nat-hazards-earth-syst-sci.net/6/621/2006/.

Krahn, J.: The 2001 R. M. Hardy Lecture: The limits of limit equilibrium analyses, Can. Geotech. J., 40(3), 643-660, 2003.

Kunapo, J., Dasari, G. R., Phoon, K. K., and Tan, T. S.:Development of a Web-GIS based geotechnical information system, J. Comput. Civ. Eng., 19(3), 323-327, 2005.
Lan, H. and Martin, C. D.: A digital approach for integrating geotechnical data and stability analyses, in: Rock Mechanics: Meeting Society's Challenges and Demands, edited by: Eberhardt, E., Stead, D., and Morrison, T., London, Taylor \& Francis, 45-52, 2007.

Lan, H. X., Zhou, C. H., Wang, L. J., Zhang, H. Y., and Li, R. H.: Landslide hazard spatial analysis and prediction using GIS in the Xiaojiang watershed, Yunnan, China. Eng. Geol., 76(1-2), 109-128, 2004.

Lan, H. X., Lee, C. F., Zhou, C. H., and Martin, C. D.: Dynamic characteristics analysis of shallow landslides in response to rainfall event using GIS, Environ. Geol., 47(2), 254-267, 2005.

Guglielmetti, V., Grasso, P., Mahtab A., and Xu, S.: Mechanized tunnelling in urban areas: design methodology and construction control, London, New York, Taylor \& Francis, pp.507, 2008.

Morgan, A. J., Roger, C. P., and Corey, R. F.: Ancestral buried valleys of the Peace River: Effects on the Town of Peace River, in: Conference Proceedings of the 61st Canadian Geotechnical Conference, Edmonton, Alberta, September, 1219-1226, 2008.

Morgenstern, N. R. and Martin, C. D.: Keynote lecture, Landslides: Seeing the ground, in: Proceedings 10th International Symposium on Landslides and Engineered Slopes, Xi' an, China, edited by: Chen, Z., Zhang, J., Li, Z., Wu, F., and Ho, K., Taylor \& Francis, London, 1, 3-23, 2008.

Nathanail, C. P. and Rosenbaum, M. S.: Spatial management of geotechnical data for site selection, Eng. Geol., 50(3-4), 347356, 1998.

Parsons, R. L. and Frost, J. D.: Interactive analysis of spatial subsurface data using GIS-Based tool, J. Comput. Civ. Eng., 14(4), 215-222, 2000.

Parsons, R. L. and Frost, J. D.: Evaluating site investigation quality using GIS and geostatistics. J. Geotech. Geoenviron. Eng., 128(6), 451-461,2002.

Renaud, J. P., Anderson, M. G., Wilkinson, P. L., Lloyd, D. M., and Wood D. M.: The importance of visualisation of results from slope stability analysis, in: Proceedings of the Institution of Civil Engineers-Geotechnical Engineering, 156(1), 27-33, 2000.

Ruel, M. A.: An investigation and analysis of a landslide at mile 47.6 Peace River railway subdivision, Unpublished Masters of Engineering Report., University of Alberta, Edmonton AB, Canada, 1988.

Solheim, A., Bhasin, R., De Blasio, F. V., Blikra, L. H., Boyle, S., Braathen, A., Dehls, J., Elverhoi, A., Etzelmuller, B., Glimsdal, S., Harbitz, C. B., Heyerdahl, H. K., Hoydal, O. A., Iwe, H., Karlsrud, K., Lacasse, S., Lecomte, I., Lindholm, C., Longva, O., Lovholt, F., Nadim, F., Nordal, S., Romstad, B., Roed, J. K., and Strout, J. M.: International Centre for Geohazards (ICG): Assessment, prevention and mitigation of geohazards, Norw. J. Geol., 85(1-2), 45-62, 2005.

Tsai, Y. C. and Frost, J. D.: Using geographic information system and knowledge base system technology for real-time planning of site characterization activities, Can. Geotech. J., 36(2), 300-312, 1999. 